\title{
UJI SENSITIVITAS MYCOBACTERIUM TUBERCULOSIS TERHADAP OBAT ANTI TUBERKULOSIS PADA PENDERITA TUBERKULOSIS PARU DENGAN DIABETES MELITUS
}

\author{
Elsa Yuniarti \\ Jurusan Biologi FMIPA Universitas Negeri Padang. \\ Jl. Prof. Dr. Hamka Padang \\ E-mail:dr_elsa@fmipa.unp.ac.id
}

\begin{abstract}
Diabetes mellitus is a chronic disease marked with high blood sugar levels. Patients with diabetes mellitus susceptible to pulmonary tuberculosismaking it difficult for to cure them. This research aims to find out figure of anti tuberculosis drug resistance in patients with pulmonary tuberculosis with diabetes mellitus. This descriptive research was conducted in the Laboratory of Microbiology Center for Lung Disease Treatment Lubuk Alung West Sumatra. Sputum samples were pulmonary tuberculosis patients with diabetes mellitus as many as 10 samples. The results of Mycobacterium tuberculosis sensitivity to anti-tuberculosis drugs in patients with pulmonary tuberculosis with diabetes mellitus showed resistance to one drug, isoniazid by $10 \%$ and the other anti tuberculosis drugs are not resistance.
\end{abstract}

Key words : diabetes mellitus, pulmonary tuberculosis, anti tuberculosis drugs, resistance

\section{PENDAHULUAN}

Tuberkulosis paru adalah suatu penyakit infeksi kronik yang sudah sangat lama dikenal pada manusia, hampir seluruh tubuh manusia dapat terserang olehnya tetapi yang paling banyak adalah organ paru. Tuberkulosis paru sampai saat ini masih tetap menjadi masalah kesehatan dunia yang utama (Amin dan Bahar, 2006). Tuberkulosis paru merupakan penyakit menular yang disebabkan oleh Mycobacterium tuberculosis yang dapat menyerang paru dan organ tubuh lainnya. Faktor yang mempengaruhi kemungkinan seseorang menderita tuberkulosis paru adalah daya tahan tubuh yang rendah, diantaranya infeksi HIV/AIDS dan malnutrisi (gizi buruk) (Depkes RI, 2007).

Tuberkulosis paru sampai saat ini menjadi masalah kesehatan di seluruh belahan dunia, terutama di negara berkembang seperti Indonesia. Tuberkulosis paru menduduki urutan kedua sebagai penyebab kematian di Indonesia setelah penyakit kardiovaskular pada semua golongan usia dan nomor satu dari golongan penyakit infeksi parvelensi basil tahan asam
(BTA) positif sebesar $0,8 \%$. Indonesia sendiri menempati peringkat ke-3 setelah India dan China dari 22 negara di dunia dengan jumlah penderita tuberkulosis terbanyak (Gedurnas TB, 2010).

Menurut WHO pada tahun 2008 menyatakan bahwa sekitar 1700 juta orang telah terinfeksi tuberkulosis paru, 3 juta meninggal dunia, dan 2,5 juta penderita berada di Asia. Di Indonesia ditemukan 500 ribu penderita baru dengan basil tahan asam (BTA) positif dan 175 ribu di antaranya meninggal dunia. Di negara berkembang kematian tuberkulosis paru merupakan $25 \%$ dari seluruh kematian yang sebenarnya dapat dicegah. Diperkirakan 95\% penderita tuberkulosis paru terdapat pada kelompok usia produktif (15-50) tahun (Departemen Kesehatan Republik Indonesia, 2002). Bersamaan dengan meningkatnya kasus tuberkulosis paru, terjadi pula kasus tuberkulosis paru yang resistensi terhadap beberapa obat anti tuberkulosis termasuk resistensi terhadap obat isonizad (INH) dan rimfapicin atau tanpa resistensi obat lain (Suradi dan Surjanto, 2004). 
Diabetes melitus adalah suatu kumpulan gejala yang timbul pada seseorang yang disebabkan oleh karena adanya peningkatan kadar glukosa darah akibat kelainan sekresi insulin dan gangguan kerja insulin. Diabetes melitus merupakan suatu penyakit menahun yang ditandai dengan peninggian kadar gula darah, apabila penyakit ini tidak terkendali maka akan menimbulkan komplikasikomplikasi yang dapat berakibat fatal atau keadaan cacat. Diabetes melitus dapat menyerang segala lapisan umur dan sosioekonomi (Syafril, 1996). Peningkatan insiden tuberkulosis paru pada penderita diabetes melitus telah banyak dilaporkan, demikian juga penyakit diabetes melitus pada penderita tuberkulosis paru. Adanya tuberkulosis paru dengan diabetes melitus sering kali menyulitkan terhadap keduanya, maka haruslah waspada terhadap perubahan metabolisme karbohidrat. Pada penderita tuberkulosis paru, kebanyakan ahli berpendapat sama yaitu para pengidap penyakit diabetes melitus mudah terserang penyakit tuberkulosis paru. Makin berat diabetes melitus yang diderita seseorang makin besar kemungkinan terkena tuberkulosis paru dan makin berat penyakitnya. Angka prevelensi tuberkulosis paru dengan diabetes melitus di Indonesia cukup tinggi. Sukarta mendapatkan angka prevelansi 14,6\%, menurut Wiyono $18,1 \%$, menurut Askandar Tjokoprawiro 16\%, menurut Hadiarto 5,9\%. Laporan penelitian oleh Soetojo di RS Persahabatan Jakarta didapatkan penyakit diabetes melitus pada tuberkulosis paru adalah 5,6 yaitu pada penderita wanita sebanyak $39,2 \%$ dan penderita pria $61,8 \%$ (Fordiastiko, 1995).

Pengobatan dan perawatan tuberkulosis paru merupakan pengobatan jangka panjang apalagi pada penderita diabetes melitus. Kedua hal tersebut merupakan keadaaan yang sering disebut sebagai tuberkulosis diabetika yang ditandai dengan perjalanannya alat eksudatif dan cepat mengalami perlajuan serta aktivitas. Kombinasi penyakit ini tidak menjadi masalah asalkan kedua penyakit ini diobati sekaligus. Penyakit diabetes seringkali tidak terdeteksi sehingga penyembuhan tuberkulosis kurang baik (Wibowo, 1990).

Saat ini peningkatan kasus tuberkulosis paru suatu penyakit infeksi disebabkan bakteri Mycobacterium tuberculosis sejalan dengan peningkatan kasus tuberkulosis paru yang resisten terhadap antibiotika obat anti tuberkulosis (OAT) khususnya di negara berkembang termasuk Indonesia. Para peneliti memperkirakan \pm 50 juta orang terinfeksi strain Mycobacterium tuberculosis yang resistensi paling tidak satu macam OAT. Resistensi merupakan persoalan dan tantangan. Pengobatan tuberkulosis paru dilakukan dengan beberapa kombinasi obat karena penggunaan obat tunggal akan cepat dan mudah terjadi reistensi. Di samping itu resistensi terjadi akibat kurangnya kepatuhan pasien dalam minum obat. Melihat lamanya pengobatan tuberkulosis, diperlukan kepatuhan pasien tuberkulosis paru untuk teratur mengikuti pengobatan hingga tuntas. Pengobatan tidak teratur, penggunaan OAT tidak teratur ataupun pengobatan terputus menimbulkan kuman yang resistensi terhadap OAT secara meluas atau MDR (Multi-drug resistance) (Masniari, 2007).

Multi-drug resistance (MDR) tuberkulosis paru menjadi masalah besar di dalam pengobatan tuberkulosis paru sekarang ini. MDR merupakan suatu keadaan yang sangat berbahaya dan pengobatannya sulit serta mahal. Pengembangan pengobatan tuberkulosis paru yang efektif merupakan hal yang penting untuk menyembuhkan pasien dan menghindari MDR. Penderita tuberkulosis paru cenderung terjadi reaktivitas dan salah satu kondisi yang dapat menyebabkan reaktivitas ini adalah diabetes melitus. Berdasarkan penelitian yang dilakukan oleh Bashar di Jakarta tahun 2001 didapatkan angka MDR-TB pada penderita tuberkulosis paru dengan diabetes melitus sebesar 36\%, sedangkan penelitian yang dilakukan oleh Suradi di Surakarta tahun 2002 didapatkan angka resistensi pada penderita tuberkulosis paru dengan diabetes melitus sebesar 33\% (Suradi dan Surjanto, 2004)

Berdasarkan data dari Dinas Kesehatan Propinsi Sumatera Barat (2009) jumlah penderita tuberkulosis paru klinis adalah 20.167 orang sedangkan untuk jumlah penderita BTA (+) sebanyak 3.489 orang dari 19 kabupaten/kota di Sumatera Barat. Di Sumatera Barat ada 4 kota yang memiliki kasus tuberkulosis paru terbanyak yaitu kota Padang 520 kasus, kabupaten Padang Pariaman 457 kasus, kabupaten Pesisir Selatan 406 kasus dan kabupaten Agam 359 kasus. Setelah di amati 
ternyata kota Padang merupakan kota dengan penemuan BTA (+) tertinggi di Sumatera Barat.

Balai pengobatan penyakit paru (BP4)

Lubuk Alung, Sumatera Barat adalah tempat pelayanan kesehatan khusus paru di Propinsi Sumatera Barat yang melayani semua rujukan penyakit paru, dengan temuan kasus terbanyak yaitu penyakit tuberkulosis paru. Pasien di balai pengobatan penyakit paru (BP4) Lubuk Alung, Sumatera Barat juga merupakan penyumbang terbesar temuan kasus tuberkulosis paru (lebih $50 \%$ ) untuk propinsi Sumatera Barat.

Berdasarkan uraian di atas dilakukan penelitian tentang uji sensitivitas Mycobacterium tuberculosis terhadap OAT yang diisolasi dari sputum penderita pasien tuberkulosis paru dengan diabetes melitus yang BTA positif di balai pengobatan penyakit paru BP4 Lubuk Alung, Sumatera Barat.

\section{METODE PENELITIAN}

Penelitian ini adalah penelitian deskriptif yang diilaksanakan dari Juni sampai Desember 2011 di Laboratorium Mikrobiologi Balai Pengobatan Penyakit Paru-Paru (BP4) Lubuk Alung Sumatera Barat. Populasi adalah penderita tuberkulosis paru dengan diabetes melitus yang berobat di balai pengobatan penyakit paru (BP4) Lubuk Alung, Sumatera Barat. Sampel yang digunakan adalah total sampling yaitu pasien tuberkulosis paru dengan diabetes melitus yang BTA positif dari bulan Juni sampai Desember terjaring sebanyak 10 sampel yang berobat di balai pengobatan penyakit paru (BP4) Lubuk Alung, Sumatera Barat.

\section{Persiapan Alat dan Bahan}

Alat yang digunakan dalam penelitian ini adalah neraca analitik, labu erlenmeyer, beaker glass, gelas ukur, mixer, vortex mixer, corong lapis, kain kasa steril, pipet ukur, tabung reaksi ukuran $1,8 \times 18 \mathrm{~mm}$ dan $1,6 \times 16 \mathrm{~mm}$, tabung reaksi ukuran $2 \times 15 \mathrm{~mm}$ berisi bead glass, koagulator, kompor listrik, autoklaf, oven, ose, lidi steril, objek glass dan lampu bunsen.

Bahan yang digunakan adalah basic fuchsin, etanol 96\%, HCL pekat, methylen blue, phenol kristal, aquadestillata, $\mathrm{NaOH} 4 \%$, serbuk obat anti tuberkulosis (Rifampicin, Isoniazid, Streptomycin dan Etambutol), PNB (Pnitrobenzoic acid), dan natrium dimetil formamid, media Ogawa 3\% dan Lowestein Jensen (LJ)

\section{Prosedur Penelitian \\ Pengumpulan Sampel (Sputum)}

Sampel berupa sputum, dikumpulkan dari 10 sampel penderita tuberkulosis paru dengan diabetes melitus yang ada di BP4 Lubuk Alung, Sumatera Barat.

\section{Pembuatan preparat (sediaan sputum) dan pewarnaan Zeihl Neelsen \\ Nomor identifikasi (register}

laboratorium) ditulis pada bagian atas kiri kaca sediaan. Pot dahak dan kaca sediaan yang beridentitas sama diambil dengan pot dahak. Pot dibuka dengan hati-hati untuk menghindari terjadi droplet (percikan dahak). Ose dipanaskan diatas nyala api spiritus samapi merah dan dibiarkan sampai dingin. Sedikit dahak diambil dari bagian yang kental dan kuning kehijau-hijauan (purulen) dengan menggunakan ose yang sudah dibakar atau menggunakan lidi steril. Dahak dioleskan secara merata dengan membuat bulatan seperti spiral pada permukaan kaca sediaan dengan ukuran $2 \times 3 \mathrm{~cm}$. Ose dimasukan ke dalam botol berisi pasir alkohol 70\%, kemudian digoyanggoyangkan untuk melepaskan partikel yang melekat pada ose, kalau menggunakan lidi, lidinya langsung dibuang ke dalam desinfektan. Setelah itu dekatkan ose pada api spritus sampai kering, kemudian dibakar sampai membara. Sediaan dikeringkan di udara terbuka, tidak boleh terkena sinar matahari langsung atau diatas api. Pinset digunakan untuk mengambil sediaan yang sudah kering pada sisi yang berlabel dengan hapusan dahak menghadap ke atas. Sediaan yang telah kering dilewatkan di atas lampu spritus sebanyak tiga kali (memerlukan waktu sekitar 3-5 detik) untuk fiksasi. Sediaan yang telah difiksasi diletakkan pada rak dengan hapusan menghadap ke atas. Larutan Carbol Fuchsin 0,3\% diteteskan pada hapusan dahak sampai menutupi seluruh permukaan sediaan dahak. Sediaan dipanaskan dengan nyala api spritus sampai keluar uap selama 3-5 menit. Zat warna tidak boleh mendidih atau kering. Sediaan didiamkan selama 5 menit. Sediaan dibilas dengan air mengalir sampai zat warna yang bebas terbuang dan diteteskan dengan asam alkohol $(\mathrm{HCl}$ Alkohol 3\%) sampai warna merah fuchsin 
hilang lalu sediaan dibilas dengan air mengalir. Larutan Methylen Blue 0,3\% diteteskan pada sediaan sampai menutupi seluruh permukaan. Sediaan dibiarkan selama 10-20 detik kemudian sediaan dibilas dengan air mengalir pelan. Sediaan dikeringkan diatas rak pengering di udara terbuka jangan dibawah sinar matahari langsung. Dilihat morfologi sel di bawah mikroskop dengan lensa okuler 10 x dan objektif $100 \mathrm{x}$ menggunakan minyak imersi.

\section{Pemeriksaan Sputum dengan media ogawa 3 $\%$}

Pengolahan bahan pemeriksaaan bertujuan menghomogenkan sediaan sputum untuk membunuh mikroorganisme yang tidak diinginkan selain bakteri tahan asam dalam sediaan sputum. Bakteri tahan asam juga dipengaruhi oleh pengolahan basa, konsentrasi terlalu tinggi dan pemberian $\mathrm{NaOH}$ yang terlalu lama akan menghambat pertumbuhan bakteri. Langkah-langkah pengolahan sputum :

Sputum dimasukkan ke dalam tabung, satu bagian volume sputum ditambah 1,5 bagian volume $\mathrm{NaOH} 4 \%$. Campuran dihomogenkan dengan vortex mixer selama 10 menit kemudian diinkubasi dalam inkubator dengan suhu $37^{\circ} \mathrm{C}$ selama 15 menit untuk melarutkan spesimen. Tabung dikeluarkan dari inkubator spesimen siap untuk diinokulasi. Inokulasi/Penanaman Pada Media Ogawa $3 \%$

Pada 2 tabung media ogawa $3 \%$ diinokulasikan masing-masing $100 \mathrm{~L}$ bahan pemeriksaan yang sudah diolah. Bahan inokulasi diratakan dan harus menyebar pada permukaan media, kemudian tabung media yang telah diinokulasi diletakkan pada rak miring dan dimasukkan dalam inkubator dengan suhu $37^{\circ} \mathrm{C}$ selama 24 jam.

Tes identifikasi dengan para nitro benzoad acid (PNB) dan Uji Sensitifitas

Pembuatan Suspensi Kuman

Pembuatan suspensi kuman untuk membuat $1 \mathrm{mg} / \mathrm{ml}$ suspensi kuman dilakukan ketika pertumbuhan koloni mulai tampak pada permukaan media, koloni bakteri diambil dengan kawat ose diameter $3 \mathrm{~mm}$. Kultur asli dari setiap kasus harus disimpan dalam lemari es sampai hasil tes dikeluarkan, kalau terjadi kontaminasi tes bisa diulang. Sebanyak 2 tetes aquades steril diteteskan kedalam tabung reaksi yang berisi bead glass, kemudian diambil 1 ose penuh (3-4 koloni bakteri), lalu dimasukkan kedalam tabung reaksi. Koloni bakteri dihomogenenisasikan lagi menggunakan vortex mixer. Sebanyak $7 \mathrm{ml}$ aquades ditambahkan lagi dan dihomogenisasikan dengan menggunakan vortex mixer. Untuk mencegah terjadinya aglutinasi spontan dari bakteri botol diletakkan diatas es/didinginkan.

Pembuatan suspensi kuman untuk membuat $0,01 \mathrm{mg} / \mathrm{ml}$ suspensi untuk inokulasi. Sebanyak 0,1 ml suspensi kuman konsentrasi 1 $\mathrm{mg} / \mathrm{ml}$ dimasukkan kedalam tabung reaksi kemudian ditambahkan aquades steril, campuran tersebut dihomogenkan dengan menggunakan vortex mixer.

Inokulasi Suspensi Kuman

Suspensi kuman konsentrasi $0,01 \mathrm{mg} / \mathrm{ml}$ diinokulasikan masing-masing $100 \quad 1$ pada media Lowestein Jensen (LJ) yang tidak mengandung OAT (kontrol), kemudian pada media LJ yang mengandung PNB dan media LJ yang mengandung OAT. Tabung tersebut ditutup dan di sebar secara merata pada permukaan media, kemudian tabung diletakan pada rak dengan kemiringan $30^{\circ}$ selama 24 jam pada suhu $37^{\circ} \mathrm{C}$, Setelah 24 jam tutup tabung dicelupkan pada parafin cair dan inkubasi dilanjutkan. Pertumbuhan bakteri diamati setiap minggu (1-3 minggu) dan dibandingkan dengan kontrol.

\section{Pengamatan}

Metode pengamatan harus sistematik dan menurut standar. Pengamatan dilakukan sebanyak 100 lapang pandang sebelum melaporkan hasil "negatif". Pemulasan horizontal di atas garis bidang $2 \times 3 \mathrm{~cm}$ kirakira sama dengan 150 lapang pandang. Kuman basil tahan asam (BTA) akan terlihat sebagai batang merah dengan latar belakang biru (Depkes RI,2007). Jumlah BTA yang ditemukan adalah informasi penting untuk menentukan derajat infeksi penderita dan beratnya penyakit karena pemeriksaan ini semi kuantitatif sifatnya. Selanjutnya pelaporan dilakukan dengan skala IUATLD (International Unit Against Tuberculosis Lung Deseases) ( Depkes RI,2007).

Pembacaan hasil pemerikasaan sediaan dahak dilakukan dengan menggunakan skala IUATLD sebagai berikut :

1. Tidak ditemukan BTA dalam 100 lapang pandang, disebut negatif. 
2. Ditemukan 1-9 BTA dalam 100 lapang pandang, ditulis jumlah bakteri yang ditemukan.

3. Ditemukan 10-99 BTA dalam 100 lapang pandang, disebut + atau $(+1)$.

4. Ditemukan 1-10 BTA dalam 1 lapang pandang, disebut ++ atau $(+2)$, minimal dibaca 50 lapang pandang.

5. Ditemukan $>10$ BTA dalam 1 lapang pandang, disebut +++ atau(+3), minimal dibaca 20 lapang pandang.

Catatan : Bila ditemukan 1-3BTA dalam 100 lapang pandang, pemeriksaan harus diulang dengan spesimen dahak yang baru. Bila hasilnya tetap 1-3 BTA, hasilnya dilaporkan negatif. Bila ditemukan 4-9 BTA, dilaporkan positif.

Pertumbuhan Koloni

Pada umumnya tanda pertumbuhan yang khas dari Mycobacterium tuberculosis akan tampak dalam waktu 3-4 minggu. Koloninya berwarna kuning muda, permukaan kering dan rapuh, dengan sudut yang tidak rata. Pertumbuhan ini disebut eugenic. Penegasan/kepastian tentang Mycobacterium tuberculosis harus dilakukan dengan tes identifikasi dengan media PNB. Kultur diamati pada hari ke-7 untuk golongan yang tumbuhnya cepat dan pada minggu ke-4 untuk golongan yang tumbuh lambat. Koloni yang tampak pada media diperiksa dengan dibuat preparat dan diwarnai dengan Ziehl Neelsen untuk memastikan BTA. Jika sudah minggu ke-4 tidak terlihat adanya koloni dilanjutkan inkubasi selama 8 minggu sebelum hasilnya dinyatakan negatif. Untuk yang positif dilanjutkan uji sensitifitas.

Pencatatan dan Pelaporan Hasil

Pelaporan dilakukan bukan hanya jumlah koloni yang tumbuh, tetapi juga bentuk tumbuhnya. Menurut (Aditama \& Luthni ,2002) pelaporan hasil biakan menurut WHO, Technic Guide 67 adalah :

$\begin{array}{lll}\text { Koloni } & : & \text { Pelaporan } \\ \text { Tidak tumbuh } & : & 0 \\ \text { Kontaminasi } & : & \text { y } \\ \text { 1-5 koloni } & : & \text { ditulis } \\ \text { jumlahnya } & & \\ 6-24 & : & 6 \\ 25-100 & : & 7 \\ >100 & : & 8 \\ \text { Koloni merata } & : & 9\end{array}$

Tes Identifikasi dengan Para Nitro Benzoad Acid (Pnb) dan Uji Sensitifitas

Uji PNB adalah untuk menentukan spesies Mycobacterium tuberculosis, PNB menghambat pertumbuhan dari Mycobacterium tuberculosis, jika pada media PNB tumbuh koloni berarti bukan spesies Mycobacterium tuberculosis. Tes kepekaan terhadap obat di dalam tabung menunjukkan kemampuan proporsi substansi dari jumlah bakteri yang ditumbuhkan dalam konsentrasi obat dan hal ini menggambarkan kemungkinan efek pengobatan terhadap penderita.

Pembacaan Pertumbuhan Koloni

$\begin{array}{lll}0 & : & \text { negatif } \\ \text { y } & : & \text { kontaminasi } \\ 1-5 \text { koloni } & : & \text { ditulis jumlahnya } \\ 5 & : & 1-5 \text { koloni } \\ 7 & : & 24-100 \text { koloni } \\ 8 & : & >100 \text { koloni } \\ 9 & : & \text { tumbuh merat }\end{array}$

Interprestasi Hasil Uji Resistensi dan Uji Sensitivitas

Untuk menghitung selisih pertumbuhan koloni di media LJ yang mengandung OAT dengan pertumbuhan koloni pada media kontrol adalah Resistensi bila sama atau lebih kecil dari 2 koloni sedangkan sensitivitas bila perbedaan lebih dari 2 koloni

\section{Analisis Data}

Pengolahan data dalam penelitian ini adalah melakukan uji persentase tingkat resisten kuman terhadap masing-masing OAT atau tingkat resistensi kuman terhadap beberapa OAT.

Proporsi $=\underline{\text { Jumlah tes resistensi positif }} \times 100 \%$ Jumlah pasien

\section{HASIL DAN PEMBAHASAN}

Hasil penelitian dari sputum penderita tuberkulosis dengan diabetes melitus sebanyak 10 sampel semuanya terdapat pertumbuhan Mycobacterium tuberculosis tidak ada yang terkontaminasi. Hasil uji sensitivitas Mycobacterium tuberculosis menunjukkan resistensi terhadap satu obat yaitu isoniazid sebesar $10 \%$, sedangkan OAT yang lain tidak terdapat resistensi (lihat Gambar 1). 


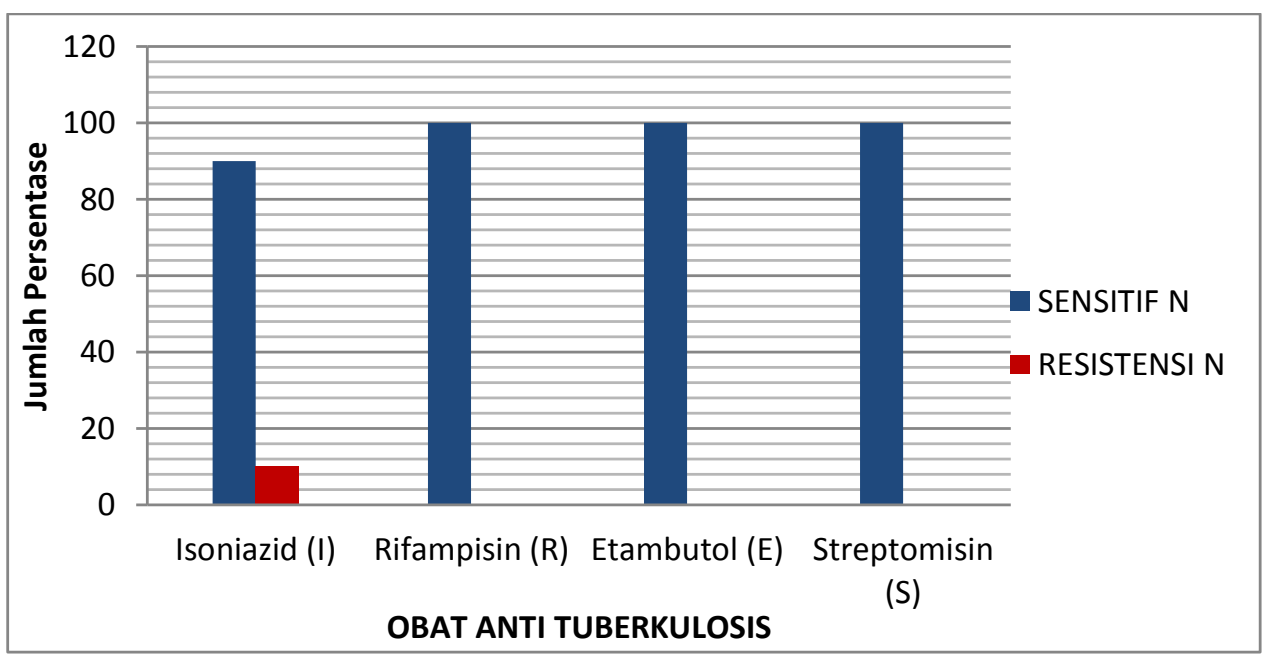

Gambar 1 Hasil Uji Sensitivitas Mycobacterium Tuberculosis terhadap OAT

Hasil uji sensitivitas Mycobacterium tuberculosis pada penderita tuberkulosis paru dengan diabetes melitus terdapat satu macam obat yang resistensi yaitu isoniazid sebesar $(10 \%)$ sedangkan OAT lainnya tidak terdapat resistensi yaitu rimpafisin $0 \%$, streptomisn $0 \%$, dan etambutol 0\%. Dari hasil data yang didapat peneliti yaitu isoniazid yang telah dilakukan uji sensitivitas datanya lebih tinggi dibandingkan dari data penelitian yang dilakukan oleh Alicia dkk di Fhilipina tahun 1999 yaitu 4,3\% (Robert dkk, 2003). Hal ini sesuai dengan penelitian dirumah sakit Canada yang melaporkan resistensi terhadap isoniazid merupakan resistensi yang paling sering terjadi (Mansyur, 2001). Pasien diabetes sangat rentan terhadap infeksi sehingga infeksi terhadap diabetes melitus bisa menjadi lebih berat. Pada penderita tuberkulosis paru dengan diabetes melitus mudah terjadi resistensi karena pada penderita diabetes melitus daya tahan tubuhnya rendah dan kadar gula darah yang tinggi sehingga mudah terinfeksi tuberkulosis paru (Simion, 2007). Disamping itu keadaan kadar gula darah yang tinggi mengganggu fungsi makrofag alveolus sehingga penyakit tuberkulosis paru yang terjadi pada penderita diabetes melitus lebih berat dan agresif serta kerusakan paru yang timbul lebih parah dan sering resistensi terhadap obat anti tuberkulosis. Penderita tuberkulosis paru dengan diabetes melitus yang mendapat pengobatan, keadaan gula darah yang tinggi mengganggu absorbsi obat saluran cerna dan kadar obat yang sampai kejaringan tidak memadai sehingga menimbulkan resistensi obat anti tuberkulosis (Bashar dkk, 2001).

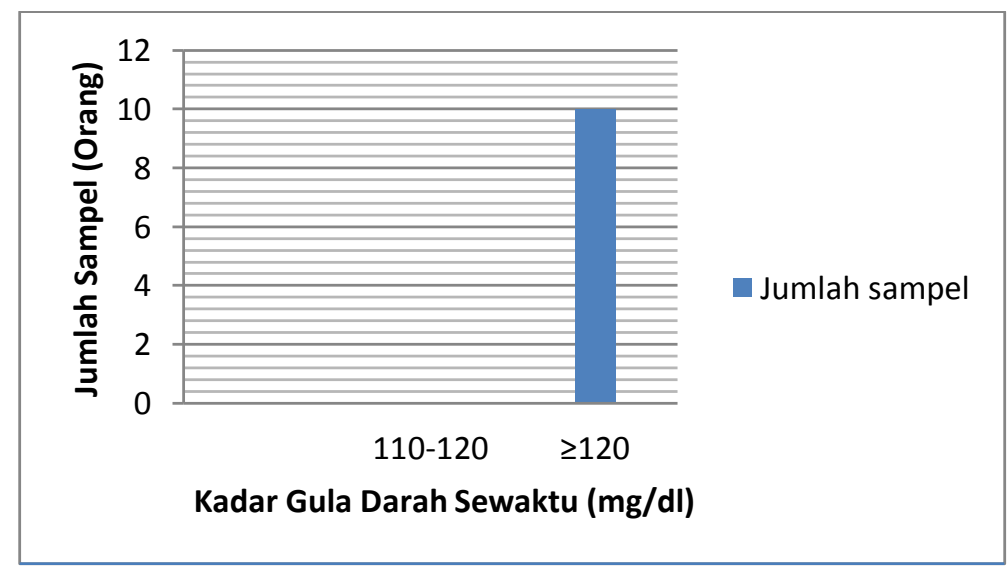

Gambar 2. Kadar Gula Darah Sewaktu (mg/dl) 
Distribusi sampel hasil kadar gula darah pada gambar 2. Penderita tuberkulosis paru dengan diabetes melitus semuanya termasuk kadar gula darah lebih dari harga normal yaitu lebih besar dari $120 \mathrm{mg} / \mathrm{dl}$, sedangkan penderita dengan kadar gula darah normal yaitu 110-120 $\mathrm{mg} / \mathrm{dl}$ tidak ditemukan.

Gambar di atas adalah kadar gula darah sewaktu yaitu besar dari $120 \mathrm{mg} / \mathrm{dl}$ yang merupakan kadar gula darah lebih dari harga normal, kadar gula darah normal yaitu 110-120 $\mathrm{mg} / \mathrm{dl}$. Keadaan kadar gula darah sewaktu yang tinggi dapat mengganggu fungsi makrofag yang dapat menimbulkan kerusakan paru yang lebih parah. Perlunya dilakukan pemeriksaan kadar gula darah karena banyak penderita tuberkulosis paru yang tidak merasakan adanya penyakit diabetes melitus sebelumnya, sehingga mengakibatkan penyakit tuberkulosis paru pada diabetes melitus lebih berat dan agresif serta kerusakan paru yang timbul lebih parah sering terjadi resistensi terhadap obat anti tuberkulosis (Suradi dkk, 2004).

Aditama (2004) dan Manginate (2000) memaparkan penyebab dari resistensi kuman tuberkulosis yaitu pemakaian obat tunggal, penggunaan obat yang tidak memadai, baik karena jenis obat yang tidak tepat. Penyebab lain terjadinya resistensi terhadap OAT menurut Rosana dkk (2005) kurang tersedianya fasilitas laboraturium yang memadai untuk melakukan uji sensitivitas dapat merupakan faktor yang berhubungan dengan terjadinya kegagalan terapi pada penderita tuberkulosis.

\section{KESIMPULAN DAN SARAN}

Berdasarkan penelitian yang telah dilaksanakan, maka dapat disimpulkan hasil uji sensitivitas Mycobacterium tuberculosis terhadap OAT pada penderita tuberkulosis paru dengan diabetes melitus didapatkan hasil resistensi terhadap satu obat yaitu isoniazid sebesar $10 \%$ dan OAT yang lainnya tidak terdapat resistensi. Pada penelitian ini uji resistensi hanya dilakukan untuk obat anti tuberkulosis (OAT) yaitu isoniazid, rifampisin, streptomycin, dan ethambutol, sedangkan untuk pirazinamid tidak dilakukan sebab teknik yang dilakukan khusus. Perlu disediakan fasilitas untuk kultur dan uji sensitivitas OAT agar semua penderita tuberkulosis paru dengan diabetes melitus dapat dilakukan uji resistensi untuk mencegah terjadinya kegagalan terapi pada penderita tuberkulosis paru dengan diabetes melitus.

\section{DAFTAR KEPUSTAKAAN}

Aditama, T.Y dan Luthni E. 2009. Buku Petunjuk Teknik Pemeriksaan Laboratorium Tuberkulosis Edisi II. Jakarta

Aditama T.Y. 2004. Mott dan Multidrug Resistens. J Resp Ind, 42:157

Amin, Z dan Bahar A. 2006. Tuberkulosis Paru Dalam Buku Ajar Ilmu Penyakit Dalam Jilid II Edisi V. Jakarta; FKUI

Bashar M, Alcabes P, dan Rom W.N. 2001. Increased Incidence Of Multidrug Resistant Tuberculosis In Diabetic. Jakarta : ECG

Depkes RI. 2007. Pedoman Penanggulangan Tuberkulosis Edisi 2. Cetakan Kedua. Jakarta Depkes RI

Depkes RI. 2008. Pedoman Penaggulangan Tuberkulosis Edisi 2. Cetakan Kedua. Jakarta Depkes RI

Dinas Kesehatan Provinsi Sumatera Barat. 2009. Profil Kesehatan Provinsi Sumatera Barat. Website: http//www.dinkes-sumbar.org

Fordiastiko. $1995 . \quad$ Penatalaksanaan Tuberkulosis Paru Pada Penderita Diabetes Melitus. Majalah paru

Guptan, A dan Ashok S. 2000. Tuberculosis and Diabetes Melitus An Appraisal. Indian Journal of Tuberculosis. 5 (2). $\mathrm{http} / / \mathrm{www} . m e d i n d . n i c . i n$

Mansyur. 2001. The Pattern Of Antituberculosis Drug Resistenin Pulmonary Tuberculosis Pattient. Journal Respirologi Indonesia. 21: 2427.

Masniari L, T.Y Aditama, dan W.H Wiyono . 2005. Penilaian Hasil Pengobatan Tb Paru dan Faktor-Faktor yang Mempengaruhi serta Alasan Berobat di RS Persahabatan Jakarta. J Respir Indo. 27 (3)

Nikmawati, Windarwati, dan Hardjoeno. 2006. Resistensi Mycobacterium tuberkulosis terhadap Obat Anti Tuberkulosis. Indonesian Journal of Clinical Pathology and Medical Laboratory. 12 (2): 58-61 
Robert J, Trystram D, Pernot C.T. 2003. Multidrug Resistant Tuberculosis. Prancis: EGC

Simion S. 2007. Multidrug Resistence (MDR) Pada Penderita Tuberkulosis Paru Dengan Diabetes Melitus. Tesis. Fakultas Kedokteran Universitas Negeri Sumatera Utara.

Suradi, J dan Surjanto. 2004. Diabetes Melitus dan Tuberkulosis Paru. Makalah disampaikan dalam simposium diabetes melitus. Semarang 15 Juli 2004

Syafril, S. 1996. Konsesus Pengelolahan Diabetes Melilitus Indonesia. Makalah Disampaikan Dalam Simposium Diabetes
Melitus Dan Penyakit Degeneratif. Padang 19 Oktober 1996.

Tim Gerakan Terpadu Nasional Penaggulangan Tuberkulosis (GEDURNAS - TB). 2007. Pedoman Nasional Penanggulangan Tuberkulosis. Jakarta: Depkes.

UPTD Balai Pengobatan Penyakit Paru (BP4). 2010. Laporan Kegiatan Balai Pengobatan Penyakit Paru (BP4). Lubuk Alung, Sumatera Barat.

Warta GEDURNAS TB. 2010. Buletin Triwulan Warta GEDURNAS TB. Volume 16. Februari 2010. Jakarta

Wibowo, S. 1990. Pengobatan Tuberkulosis Paru. Cermin Dunia Kedokteran: 50-52 